\title{
ESTUDOS
}

\section{Representações de professores sobre cotidiano escolar}

\begin{abstract}
Lúcia Velloso Maurício
\section{Resumo}

Procura compreender a resistência dos professores a um processo de mudança. A pesquisa, realizada em escola estadual de ensino fundamental num município de periferia do Rio de Janeiro, desenvolveu-se em período em que a escola passou por uma série de transformações. A análise da representação dos professores a respeito do próprio professor, do aluno, de seu comportamento, de reuniões, de diretor e de escola e de educação possibilitou desmembrar em dois grupos a categoria de Nildecoff "professorprofessor" e construir perfil das categorias professores "outros" e "próprios": os outros atribuem a outros a responsabilidade pelo processo educacional; os próprios se reconhecem como agentes do processo educacional. Dos 48 entrevistados, 30 ficaram na categoria outros e 18, na categoria próprios.
\end{abstract}

Palavras-chave: prática escolar; democratização da escola; resistência à mudança; delegação de poder.

\section{Abstract}

Teachers' representations about every day school practices

This study intended to investigate the resistance of teachers to changes in their work environment. The research, developed in a primary public school, in a suburb of Rio de Janeiro, took place in a moment in which a democratic project introduced many changes in the school environment. The ethnographic observations and the analyses of 48 interviews by Bardin's point of view allowed separate in two Nilkdecoff's category "teacher-teacher". The analyses of the teachers' representations about the principal, the school, themselves, pupils, their behavior, meetings and education made possible to build the profile of the categories 'others' and 'selves': the first ones don't feel as if they were responsible for school determinations; the 'selves' recognize that teachers and students may determine the orientations of the school development. Among 48 interviewers, 30 were categorized as others while 18 , as selves.

Keywords: school practices; school democratization; resistance to changes; power transfer. 


\section{O passado no presente}

Em momento como diretora de escola pública de ensino fundamental na periferia do Grande Rio, inserida em um projeto de formação de professores mediante a articulação com duas outras unidades de ensino, colocou-se como dificuldade para o desenvolvimento do projeto a descrença dos professores em propostas que alterassem sua rotina e que demandassem sua iniciativa. Atingir o objetivo de democratização do ensino não dependia apenas do aprimoramento técnico dos professores em relação à transmissão de saber; passava também pela sua disposição, pela postura como vivenciavam, no cotidiano, dentro e fora da sala de aula, a trama de relações sociais (Lima, 1988).

Como nos diz Perrenoud (1993), a transformação das práticas depende de mudança do habitus, definido como

\section{[...] sistema de disposições duradouras e transponíveis que, integrando experiên- cias passadas, funciona, em cada momen- to, como uma matriz de percepções, de apreciações e de ações, e torna possível a concretização de tarefas infinitamente diferenciadas, graças às transferências analógicas de esquemas que permitem re- solver os problemas da mesma natureza (Perrenoud, 1993, p. 39, apud Bourdieu, 1972).}

Assim, para a mudança de práticas, é necessário que haja disponibilidade de modelos para ação e indispensável à tomada de consciência da prática e do habitus. "Se não se compreender bem em que condições e com que tipo de racionalidade os professores levam a cabo o seu trabalho, não se poderá saber em que medida os resultados da investigação em educação podem incidir nas práticas." (Perrenoud, 1993, p. 36). Nessa perspectiva, a socialização de informações e a promoção de instâncias de participação, para favorecer a coletivização de decisões, tinham como pressuposto a compreensão da resistência em mudar e da descrença em sua possibilidade de ação para transformar estas atitudes, buscando a democratização das relações sociais dentro da escola.

A contínua interação com professores de ensino fundamental público em processos de educação continuada e com alunos de faculdade de formação de professores em relação de docência em instituição também pública tem consolidado a convicção de que é necessário pesquisar representações comuns a respeito de práticas escolares que levam ao processo de descrédito na própria educação.

Ainda segundo Perrenoud (1993), não se pode, em hipótese alguma, ignorar a comunicação, verbal ou não-verbal, entre professor, em geral de classe média, e alunos de origens diversas. A aceitação do outro, da afetividade e das afinidades de gosto e modo de vida joga parte importante no insucesso escolar. Condenar o professor não é útil; não adianta subestimar a razão prática. Melhor seria falar sobre este processo, discutir suas conseqüências e analisar as tomadas de decisão. Este foi o caminho buscado nesta experiência que decidimos resgatar. O que aqui se relata são práticas do cotidiano escolar na relação do professor de classe média com alunos de classes populares, em momento de reorganização da escola, portanto etapa de desestabilização das rotinas, permitindo emergir as representações que orientam as práticas cotidianas, favorecendo sua compreensão livre de obrigações hierárquicas que poderiam ocultar intenções de caráter punitivo, seja através de enquadramentos funcionais ou de direitos a gratificações.

Esta pesquisa elaborou as categorias professores outros e professores próprios, com as quais se discutiu a reação dos professores de uma escola estadual de ensino fundamental a um projeto de democratização (Maurício, 1990). A propriedade dessas categorias se mostrou pela sua pertinência, na época, para compreender processos eleitorais pelos quais a escola passou, e, em reuniões recentes, para discutir com os professores atuais da rede pública de ensino sua inserção na unidade escolar. A formulação dos perfis dos professores outros e dos professores próprios traz à pauta a discussão, trazida por Apple (1995), do predomínio crescente da docência como trabalho de mulher. O autor afirma que é muito clara a conexão entre escolarização e poder econômico, cultural e político e que essas conexões poderiam ser mais bem desveladas se entrássemos na escola para ver o que de fato ocorre. Foi o que se tentou fazer. 


\section{Contexto recuperado}

A Escola Estadual Coronel João Tarcísio Bueno, no município de São Gonçalo, fez parte do projeto chamado Complexo Educacional de São Gonçalo (Cesg). Esse projeto, primeiro campo de aplicação das diretrizes educacionais do primeiro Governo Leonel Brizola (19831986), no Estado do Rio de Janeiro, envolvia três unidades escolares de diferentes graus de ensino. Para alcançar os objetivos propostos pelo Cesg, cada uma das unidades sofreu uma série de transformações (Ribeiro, 1986). Mediante esse projeto, Darcy Ribeiro, vice-governador e presidente da Comissão Coordenadora de Educação e Cultura, pretendia colocar em funcionamento o que chamava de Escola de Demonstração, que constava das metas a serem alcançadas naquele governo.

As três unidades escolares estaduais eram situadas em torno de um terreno, em São Gonçalo, periferia do Rio de Janeiro, que há décadas era disputado na Justiça pelo Estado. As escolas, apesar da proximidade, viviam independentes umas das outras: a Faculdade de Formação de Professores (FFP), principalmente com cursos noturnos de licenciatura curta; o Centro Interescolar Walter Orlandine (CIWO), oferecendo cursos técnicos à noite; e a E.E. Cel. João Tarcísio Bueno, com quatro turnos, 3.200 alunos e precária infra-estrutura. O projeto propunha-se integrar, pedagógica e administrativamente, as três unidades escolares e construir, no terreno em disputa, tudo o que fosse necessário para este fim (Rio de Janeiro, 1983a). O projeto, viabilizado por meio de convênio entre a Secretaria Estadual de Educação (SEE), responsável pelas escolas básicas, e a Fundação de Amparo à Pesquisa, do Estado do Rio de Janeiro (Faperj), mantenedora da faculdade, tinha por objetivo buscar o atendimento às metas educacionais do governo aprovadas no Encontro de Mendes (Mignot, 1988).

A escola fundamental deveria extinguir o terceiro turno e proporcionar cinco horas de permanência na escola (meta 1); o Cesg contaria com uma escolaparque para atender aos alunos do ensino fundamental (meta 13); a educação infantil seria desmembrada do ensino fundamental de forma a ter um funcionamento autônomo, para que o Cesg viesse a funcionar como escola de demonstração (meta
16); o Cesg receberia professores de todo o Estado do Rio de Janeiro para serem atualizados mediante estágios (meta 2); o ensino médio investiria no curso de formação geral diurno, eliminando, aos poucos, os cursos profissionalizantes (meta 17); a Faculdade seria reestruturada para funcionar integradamente com a educação infantil, o ensino fundamental e médio, onde seus alunos fariam estágio desde o ciclo básico; os cursos de licenciatura curta seriam extintos, e o horário diurno priorizado; seria criada uma Escola Normal Superior (meta 18) (Rio de Janeiro, 1983b).

O fracasso do Estado em conseguir, de imediato, a posse do terreno inviabilizou a infra-estrutura necessária para a instalação do projeto. Como as diretoras das unidades já estavam nomeadas, a improvisação foi a tônica da implantação do Cesg, causando graves seqüelas e comprometendo a possibilidade de sua realização. Desde o início, as conquistas deveram-se ao esforço das diretoras e equipes locais e a soluções específicas, e não a uma política institucional. No final de 1986, quando a posse do terreno já estava assegurada e dois Centros Integrados de Educação Pública (Cieps) ${ }^{1}$ estavam sendo construídos para integrarem o complexo, Darcy Ribeiro perdeu a eleição para governador, tornando-se inviável a continuidade do projeto. $\mathrm{O}$ decreto de criação do Cesg e a resolução que previa seu funcionamento foram publicados na última semana de governo, na esperança de que pudessem servir de apoio à continuidade do projeto, mas as condições políticas não existiam mais (Rio de Janeiro, 1985).

\section{De uma escola pública qualquer para uma escola colorida $^{2}$}

Três características baseavam a organização das escolas estaduais até aquela época: falta de vagas (para alunos), falta de professores (para dar aula) e falta de verbas (para manutenção das escolas, salários dos professores, gratificação de diretores, material didático). Esses problemas levavam à estruturação das escolas mediante a quantidade, naturalizando o pensamento quantitativo. A escola não atendia ao aluno, mas ao número de alunos, pois, com 35 numa turma de primeira

\footnotetext{
Prédios escolares projetados por Oscar Niemeyer para abrigar escolas públicas de horário integral. Ao longo dos dois governos de Leonel Brizola (1982-1986 e 19911994) foram construídos 506 Cieps no Estado do Rio de Janeiro.

2 Esta escola recebeu um projeto artístico assinado por Carlos Scliar: ela foi inteiramente pintada de azul, amarelo, vermelho, abóbora e verde, ficando conhecida como Escola Colorida, uma possível metáfora para a visão de educação que se pretendia alcançar.
} 
série, a preocupação com rendimento pedagógico da criança anulava-se. Assim, tornavam-se naturais a existência de quatro turnos, a falta de biblioteca e de laboratório (porque todas as salas tinham aula) e um número de alunos por turma além do permitido por lei (porque a evasão era natural).

A E. E. Cel. João Tarcísio Bueno organizava seus 3.200 alunos em 72 turmas em quatro turnos diários. O ensino ia de primeira a oitava série, regular diurno, e supletivo noturno. A média de alunos por turma variava em torno de 55 no supletivo, 40 de quinta a oitava série e 35 de primeira a quarta série. A distribuição das séries pelos turnos se dava de acordo com a disponibilidade de horário do professor, de modo que o docente com nível superior e bastante tempo de casa tinha prioridade na escolha do turno. A aplicação desse critério resultava que o segundo segmento funcionava no primeiro turno; o primeiro segmento no segundo turno; e o terceiro turno era composto por sobra de professores e de alunos. Entre outras conseqüências, os professores do segundo e do primeiro segmentos não tinham qualquer contato entre si, e o terceiro turno era sempre caótico, pois não atendia a qualquer critério. O turno da noite era outro universo; cedia nove salas de aula para uma escola da Campanha Nacional de Escolas da Comunidade (Cnec). ${ }^{3}$ Então, à noite, no mesmo espaço, conviviam uma escola particular e uma pública. Em suma, a organização da escola atendia à SEE e aos professores, não ao aluno.

Esse estilhaçamento da escola, em que cada turno tem seu universo próprio, desconsiderava que o aluno que mudava de um turno para o outro era o mesmo. A criança com um bom desenvolvimento saía do segundo turno ( $1^{\mathrm{a}}$ a $4^{\mathrm{a}}$ série) e ia para o primeiro $\left(5^{\mathrm{a}}\right.$ a $\left.8^{\mathrm{a}}\right)$. A que apresentava um rendimento fraco e/ou comportamento discutível deixava o segundo e cursava $5^{\text {a a }} 8^{\text {a }}$ no terceiro, e, o que era realmente indesejável, terminava o primeiro segmento no terceiro turno e provavelmente faria o segundo segmento, se fizesse, no turno da noite. Esta distribuição de turmas pelos turnos não atendia a qualquer critério explícito - o de separação dos turnos por faixa etária ou o de disponibilidade de escolha para a comunidade -, mas, sim, a um critério implícito de segmentação socioeconômica.
Não havia planejamento para a quantidade de turmas por séries; elas eram organizadas de acordo com a demanda e a quantidade de professores disponíveis aliás, a própria grade curricular acompanhava essa variável. Dessa forma, se muitos professores de $5^{\mathrm{a}}$ e $6^{\mathrm{a}}$ séries entravam de licença, diminuía-se o número de turmas dessas séries e aumentava-se o de $7^{\mathrm{a}}$ e $8^{\mathrm{a}}$; ou, então, se muitos professores de Matemática estivessem impedidos de trabalhar por um motivo ou outro, diminuíase a carga horária da disciplina. Em suma, a organização da escola atendia à SEE e aos professores, não ao aluno.

Em média, esta escola contava com 22 turmas em cada um dos três primeiros turnos, utilizando o espaço físico total em salas de aula, e com 14 turmas à noite, também o máximo possível, excetuando-se as salas cedidas. O primeiro segmento girava em torno de 36 turmas, com pelo menos 22 de primeira e de segunda série, ou seja, ocupando todo o segundo turno; o segundo segmento abrangia 30 turmas em geral, com os mais velhos estudando no primeiro turno; o terceiro turno reunia as turmas restantes dos dois segmentos; o supletivo oferecia quatro turmas de primeira a quarta fase e dez turmas de quinta a oitava fase. Percebia-se retenção de alunos nas primeiras séries do primeiro segmento (mais da metade das turmas) e evasão nas últimas; no segundo segmento essa pirâmide se repetia, com forte retenção na quinta série e evasão ou mudança de turno nas últimas. O supletivo tinha essa pirâmide invertida, pois recebia maciçamente os alunos com mais de 14 anos que abandonavam o diurno. As turmas iniciais do supletivo eram compostas por alunos com idade bem mais avançada e origem bastante diversa da dos que freqüentavam de quinta a oitava fase.

O diretor contava com os seguintes mecanismos de poder, institucionalizados ou não: controle de freqüência e abono de falta; concessão de gratificação por regência de turma; ${ }^{4}$ prioridade na escolha de turno, série, turma, horário; concessão de licença especial e de aposentadoria; devolução do professor. ${ }^{5}$ A habitual carência de professores na escola impedia que o diretor completasse sua equipe. Ao preencher as funções extraclasse, que eram posições de prestígio, o diretor tinha que "ajeitar" situações oriundas de contradições legais do Estado e criar situações atraentes para que pessoas de sua confiança quisessem 
exercê-las, ou seja, tinha que garantir a gratificação por regência de turma a quem, por lei, não tinha direito a ela. Essa situação levava à composição de uma equipe desnivelada, sem objetivos comuns, com graus variados de poder e que não gozava da confiança do professorado. Não havia reuniões regulares além dos conselhos de classe e de algumas reuniões eventuais para informes da SEE (Maurício, 1990).

Bourdieu indicava, segundo Perrenoud (1993), que mudanças nas condições objetivas de ensino davam maior contribuição a modificações da prática do que a difusão de idéias. Perrenoud argumenta que esta compreensão poderia levar a maior preocupação com os administradores escolares do que com os professores. Alerta para o fato de que a manipulação das estruturas é delicada e pode ser contraproducente se não se levar em conta as condições da prática e as aspirações dos professores. Afirma que a releitura de experiências deve ser estimulada, propiciando mais espaço para o trabalho em comum e facilitando a discussão entre os professores. Entretanto pode não surtir efeito se os professores não se sentirem à vontade para discussão com seus colegas ou se não desenvolverem sentimento de pertença à equipe pedagógica. De uma certa forma, foi o que verificamos na pesquisa efetivada. As ações adotadas, que estão descritas a seguir, revelam a pouca identificação da maioria dos professores da escola com os objetivos das mudanças que foram realizadas, levando a uma adesão superficial que caracteriza um dos perfis construídos (Maurício, 2004).

A fim de alcançar os objetivos do projeto, a primeira diretriz adotada foi restringir a quantidade. Foi extinto o terceiro turno, reduzido o número de alunos por turma e abriu-se o leque completo de turmas em cada turno. Assim, o quantitativo de turmas passou de 72 para 85 no primeiro ano de implantação do projeto, incluídas as turmas de educação infantil. Foram ocupadas 12 salas de aula da faculdade nos turnos diurnos para dar conta do aumento do quantitativo de turmas. A distribuição de turmas nos turnos e prédios estava longe de ser ideal, e as situações foram sendo corrigidas no decorrer do tempo. Por outro lado, ingressaram, fora do concurso de remoção, ${ }^{6}$ cerca de 40 professores cuja motivação, com raras exceções, era trabalhar mais próximo de suas casas. Apesar da ilusória intenção de selecioná-los, os professores continuaram a ser os que existiam no Estado, em geral, e não os que se adequariam ao projeto.

A segunda diretriz era investir na qualidade de ensino. Alunos e professores, agora com intervalo entre turnos e com toda a gama de turmas escaladas para cada turno, tiveram ampliadas suas possibilidades de troca, de conhecimento de pessoas, de consulta a professores, de conversar, ou seja, aumentaram suas possibilidades de vivência não orientada. Mas também era necessário aumentar o tempo do aluno na escola, com atividades orientadas. Como a idéia inicial do projeto era ampliar o turno através da Escola Parque, ${ }^{7}$ e como não havia professores ou salas suficientes para ampliar o tempo de permanência para todos, foram introduzidas atividades extraclasse para os alunos interessados. Paralelamente, foram oferecidas atividades eventuais tanto para professores como para alunos, a fim de que tivessem contato com campos de conhecimentos variados. Os professores tiveram cursos e assessorias em várias áreas, e os alunos assistiram a peças de teatro e tomaram parte em diversos eventos. No segundo ano do projeto, os turnos diurnos foram ampliados para cinco horas, com seis horas-aula cada.

A terceira diretriz foi fazer com que alunos e professores discutissem a vida escolar, despertassem em si mesmos o desejo de participar das decisões que eram tomadas na escola. Em relação aos professores, foi implantado um sistema em que cada equipe, por disciplina, teria reunião semanal (em dia fixo escolhido pelo grupo) e cada grupo teria um coordenador, dispensado de turma, mas com gratificação por regência de turma, de forma que pudesse participar e implementar a reformulação curricular do Cesg. Uma vez por mês, em vez de reunião por disciplina, haveria uma reunião geral, fosse da escola fundamental ou do Cesg como um todo. Como os professores não tinham hábito de se reunir, apesar do horário previsto para esse fim na carga horária de cada um, a presença nas reuniões era obrigatória e controlada, até que o hábito estivesse formado ou o interesse despertado.

No segundo ano do projeto, o sistema de reuniões melhorou muito, pois foi possível consultar os professores a respeito de suas preferências, estabelecer critérios de acordo com essa coleta de dados e

\footnotetext{
Para que um professor estatutário seja removido de uma unidade escolar para outra, por iniciativa própria, deve se submeter a um concurso que avalia pontos que são acumulados ao longo de sua carreira no Estado. Este processo, com regras comuns a todos os professores, é chamado de concurso de remoção.

7 Escola Parque foi uma proposta feita por Anísio Teixeira para que alunos do ensino fundamental, que freqüentavam a escola classe, completassem seu turno e sua formação com atividades de cunho prático, de caráter artístico ou profissional. Darcy Ribeiro inicialmente adotou esta proposta, antes de generalizar o projeto de horário integral nos Cieps.
} 
prever reuniões dentro do calendário escolar. Assim, conseguiu-se horário e dia de reuniões único, entre o primeiro e segundo turnos, comum a todas as equipes. Agora a reunião ser geral, por área ou por série, não alterava o cotidiano da escola, não excedia a carga horária de ninguém nem beneficiava uns em detrimento de outros. No último ano do projeto, em busca da integração do turno da noite e por sugestão dos professores, passou a haver uma reunião mensal aos sábados, parte de área, parte geral, de forma que os professores dos três turnos pudessem se encontrar; as reuniões de série e outras de área continuaram no sistema do ano anterior.

Todas essas modificações e o comprometimento se refletiram nas comemorações da escola, que viraram festas com grande comparecimento, organizadas pelos próprios professores, com teatros, shows, brincadeiras. Elas eram, no sentido literal da palavra, confraternizações; aquele sentimento que se tem quando se trabalha muito, quando se desgasta muito na tensão da construção coletiva, mas se alcança a realização. E para festejar, era mais trabalho ainda: os teatros, as brincadeiras, todos relacionados ao cotidiano da vida escolar, às vezes, levavam mais de um mês para serem organizados. Mas qualquer pessoa que participasse de uma daquelas festas sairia dali pensando: que lugar bom de trabalhar! (Maurício, 1990).

\section{Como distinguir as cores da escola colorida?}

Para analisar a reação dos professores, suas motivações, foram indispensáveis as observações etnográficas recolhidas ao longo do projeto e as entrevistas individuais realizadas com 48 professores. O conhecimento adquirido no cotidiano permitiu reconstituir fatos, duvidar de depoimentos e desconfiar da relação comigo construída. As observações acumuladas e a consciência de que a minha pessoa, exdiretora da escola, era portadora de significados, levaram-me a optar por entrevista individual.

O roteiro das entrevistas teve por base as diretrizes de transformação da escola redução da quantidade, investimento na qualidade e integração. Esse roteiro, montado em situações bem concretas, permitia que o professor tivesse liberdade para escolher assuntos significativos para ele, mas não deixasse de abordar aspectos essenciais para a pesquisa. Além disso, era bastante flexível, incluindo assuntos não previstos à medida que fossem aparecendo. As três primeiras perguntas foram propositalmente amplas, de forma que a memória de cada um selecionasse as situações mais significativas; as quatro seguintes, bem mais concretas, relacionavam-se à diretriz integração; duas outras foram feitas com o intuito de perceber se o professor identificou objetivos ou diretrizes nas transformações vividas; e, finalmente, uma pergunta montada através de uma metáfora para apreender a concepção de educação.

Para verificar a representatividade da amostra de entrevistados, foi levantado o total de professores da escola. Para tanto, considerou-se um ano como tempo mínimo de permanência na escola a partir da implantação do projeto. Entre os 182 professores que estiveram na escola no decorrer do projeto, 122 permaneceram três anos; 48, dois anos; e 12, um ano. A amostra correspondeu a $25 \%$ do total: 45 professores. Foram entrevistados 22 professores que permaneceram pelo menos dois anos na coordenação pedagógica da escola ou na coordenação de turno, por serem estas consideradas funções com grau de informação privilegiado a respeito do funcionamento da escola. A amostra foi completada por 23 professores sorteados, critério adotado para evitar que meu envolvimento com as pessoas pudesse levar a preferências.

Os critérios de referência para distinguir os integrantes do corpo docente foram adotados por se destacarem, na observação feita ao longo do projeto, como fatores de discriminação entre os próprios professores. Assim, foram considerados: tempo de escola; ser de São Gonçalo ou não; formação acadêmica; turno de atuação; e a disciplina lecionada. Este último aspecto foi abandonado no decorrer da pesquisa, por não ter se mostrado significativo. Houve a preocupação de que a amostra de professores selecionados fosse proporcional ao universo total de docentes em relação a cada um destes aspectos. A distinção de gênero não foi privilegiada a princípio, mas, quando configurado o universo de entrevistados, a proporcionalidade em relação a este critério foi verificada e mostrou-se coerente. 
Foram gravadas 40 fitas, transcritas em 560 , e realizados o fichamento de cada entrevista e a elaboração de índice por assunto, organizado na perspectiva de Bardin (2000). O primeiro índice temático continha os itens do roteiro, desmembrados em muitos outros, e mais 42 tópicos. Organizado um segundo índice temático, mais sucinto em número de tópicos, mas, estes, com maior abrangência, concentraram-se as informações em 16 temas, além dos estabelecidos objetivamente pelo roteiro. Este segundo índice, além de permitir visualizar com clareza os assuntos não previstos no roteiro que emanavam espontaneamente das entrevistas - disciplina, professor, diretor -, possibilitou encontrar um caminho de análise que se afastava do roteiro inicial, mas abarcava mais confortavelmente as representações colhidas dos professores.

\section{Os primeiros tons}

Logo se mostrou que os professores mais antigos eram predominantemente de São Gonçalo e tinham clara preferência pelo primeiro turno. A formação universitária deste grupo era abaixo da média da escola. Os mais novos, que entraram com o projeto, contrastavam em tudo com os mais antigos: eram preferencialmente de fora, tinham formação universitária acima da média da escola e a maioria trabalhava no segundo turno. O primeiro turno, considerado a elite da escola, tinha formação acadêmica mais baixa; e o terceiro, visto criticamente, possuía a melhor formação, indicando que esta crítica advinha de outros fatores que não a titulação acadêmica.

As três primeiras perguntas evidenciaram que a proposta do Cesg não chegou a ser conhecida e, quando foi, não significou muito para os professores em geral. Do bloco de perguntas relacionado à diretriz integração, o que ficou mais nítido foi a importância das reuniões: mesmo que muitos dissessem que não gostavam delas ou que achavam que não levavam a nada, que não as percebessem como instrumento de integração de turnos ou pessoas, ou reclamassem do seu excesso, elas apareceram em todos os depoimentos, de forma espontânea. Confirmando argumento de Perrenoud, a reunião de fato propiciou a releitura de experiências, o que não significa, ainda, mudança da prática docente.
No bloco dedicado à diretriz qualidade, poucos foram os professores que relacionaram as diversas atividades introduzidas e tiraram alguma conclusão; de maneira geral, avaliavam cada inovação no seu particular e/ou seu efeito no cotidiano imediato do professor.

Em busca de ferramentas para analisar os professores pesquisados, a categorização mais adequada estava em Nildecoff (1991). Ela dividia os professores em três grupos: professor-policial, professor-professor e professor-povo. Apesar de as categorias terem denominação um tanto forte, pois os professores da E. E. Cel. João Tarcísio Bueno pareciam, de maneira geral, muito menos conscientes do que seria o professor-policial ou o professorpovo, eles caberiam nessa divisão. Entretanto, a categoria que abarcava a maioria dos professores-professores não era desenvolvida no decorrer do livro.

A distinção dos professores foi feita mediante a pergunta "quem é o sujeito do processo educacional?”. De um lado estavam os próprios, que reconheciam em si mesmos, professores e alunos, enquanto coletivo, a possibilidade de determinarem o rumo da escola; de outro lado estavam os outros, que não reconheciam no coletivo da escola a possibilidade de serem agentes do processo educacional, atribuindo essa qualidade a outros: diretor, governo, "política”, “educação”, etc. Este delegar de poder nos remete à separação entre concepção e execução de trabalho, que, como aponta Apple, acompanha a feminilização da docência, chegando a ser tratada como desqualificação e empobrecimento.

O segundo índice temático foi reestruturado de forma a descrever cada um dos dois grupos. Com a utilização de tópicos como disciplina, código de conduta, conselho de classe e outros, que não eram perguntas do roteiro, foi sendo construída a representação de aluno. A imagem de professor perpassava as entrevistas inteiras, independentemente de itens ou roteiro. Os assuntos disciplina e reunião permitiram perceber o pensamento de cada grupo a respeito da possibilidade de autonomia do aluno e do professor. Os últimos temas utilizados para distinguir próprios de outros foram direção e escola.

O primeiro fato a destacar é que, dos 48 entrevistados, 30 , ou seja, $62,5 \%$ do 
total, ficaram na categoria outros, enquanto apenas 18 professores foram incluídos como próprios. Assim, praticamente 2/3 dos professores não se sentiam sujeitos do seu próprio trabalho, sentiam-se objetos de determinações que lhes escapava, daí a apatia, a falta de iniciativa, a indiferença com que tratavam a escola, a educação, resultados do seu próprio trabalho. Existiam conotações, nuanças, tonalidades diversas. Alguns professores outros não eram indiferentes à escola, ao contrário, muito dedicados, apesar de ingênuos e paternalistas. Os próprios, apesar de terem pensamentos bastante variados, lutavam pela escola, também de formas diversas, porque acreditavam que sua ação, e/ou também a do aluno, podia gerar mudanças, transformar desde o cotidiano da escola até a sociedade inteira; ou seja, havia uma variação enorme no alcance do pensamento desses professores, grau diferenciado de consciência da sua possibilidade de transformação.

A partir das médias da escola - 62,5 $\%$ para outros e $37,5 \%$ para próprios - foi feita a comparação de índices de distribuição de outros e próprios pelos fatores tempo de escola, município, formação e turnos. Em relação a tempo, a faixa dos mais antigos teve o mais alto índice da categoria outros, 90\%; em compensação, a faixa dos mais novos, que entraram com o projeto, teve alto índice na categoria próprios. Concluiu-se que o fator tempo mostrou-se profundamente significativo para a discriminação entre uma categoria e outra e que, quanto maior o tempo de escola, mais afastada ficava a noção de sujeito; por outro lado, quanto menor o tempo de escola, maior a proporção de professores que se sentiam sujeitos, agentes do processo educacional. $\mathrm{O}$ aspecto município também se mostrou significativo, não pelos outros, que tiveram índice de $72 \%$ dos entrevistados de São Gonçalo, mas por causa dos próprios, que alcançaram seu maior índice, $66,5 \%$, entre os professores de fora de São Gonçalo.

O segundo maior índice da categoria outros reuniu-se em torno da formação em nível médio, 83,5\% dos 30 entrevistados nessa categoria; evidentemente havia a contrapartida: os próprios alcançaram 40,5\% para o grau universitário. Assim, a formação também pareceu interferir na interiorização da noção de sujeito. O terceiro maior índice de outros apareceu no terceiro turno, $78,5 \%$ dos 30 outros entrevistados; os próprios tiveram índice $48 \%$, bastante superior à média deles, no segundo turno; o pessoal da manhã ficou na média da escola. De fato, a composição dos turnos resulta dos fatores tempo de escola, formação e município de residência. Aqui se localizou a maior concentração de pessoal progressista no segundo turno, o que é fácil de entender, pois recebeu a maioria dos professores novos com número bastante alto de residentes em Niterói e Rio de Janeiro; entretanto, o maior foco de outros por turno ficou no terceiro, exatamente o turno com maior índice de professores universitários, que implicaria pensamento mais renovador. A resistência identificada no turno da noite deve ser atribuída à motivação, pois, em geral, o nível superior desses profissionais relacionavase ao exercício da profissão diurna e não dizia respeito ao exercício do magistério.

Para sintetizar: os outros se encontravam entre os mais antigos, 90\% da categoria; entre os professores com nível médio, 83,5\%; no terceiro turno, 78,5\%; e residentes em São Gonçalo. Os próprios tiveram seu maior índice entre os moradores de Niterói e Rio, $66,5 \%$; eram novos na escola, $62,5 \%$; trabalhavam no segundo turno, 48\%; e possuíam grau universitário, 40,5\%.

Entre os professores escolhidos por critério (participantes da coordenação), os próprios tiveram 44\%, um pouco acima da média da categoria. Como implementar mudanças, se nem metade da própria direção agia num sentido de transformação? O pessoal escolhido por critério incluía não apenas a coordenação pedagógica, verdadeira direção, mas também os coordenadores de turno, executores do cotidiano; $80 \%$ destes figuraram na categoria outros. Se os implementadores do cotidiano não acreditam em mudança, a dificuldade em implantá-la amplia-se (Maurício, 1990).

\section{$O$ contraste entre as cores}

O tema professor foi o que mais se consolidou: todas as entrevistas falavam do professor, suas atitudes, seus hábitos, suas preocupações. Então, foi simples chegar aos traços do professor, mas não foi fácil saber a quem os traços pertenciam, porque os entrevistados, de maneira geral, falavam do professor em terceira pessoa, como se ele não fosse professor. O professor era 
primeiramente apegado à rotina, acomodado, acometido de inércia; em segundo lugar, estava despreparado... para quê? Para sair da rotina, para inovar, para enfrentar transformações, para ser livre, para criar. Um terceiro grupo reconheceu que havia dois tipos de professores: os acomodados e os que se envolveram, os que saíram da rotina para ir à luta. Dando os traços às categorias criadas, os outros se caracterizaram principalmente por não gostarem de sair da rotina e por não estarem preparados; apenas alguns reconheceram que havia uma divisão na escola, entre acomodados e envolvidos. Os próprios, quase todos, reconheceram esta divisão, pelo tipo de iniciativa, pelo posicionamento em reunião, etc.

O tema disciplina ficou mais transparente que o tema professor, porque a disciplina já é do outro, não diz respeito ao professor. Aqui a separação entre outros e próprios é nítida, porque, basicamente, o assunto disciplina era preocupação dos outros e não dos próprios; estes, quando se referiam à disciplina, era de forma natural, que caracterizava um processo de mudança: os alunos estavam num momento de adaptação, num rito de passagem, de um sistema autoritário e de submissão (ou revolta, ou expulsão) para um sistema democrático e de autonomia. Para os outros, a disciplina foi o grande cavalo de batalha; ela constituiu o melhor escudo para a resistência, a acomodação, a insegurança, etc. Aqui e no próximo tema, aluno, ficou bem claro que os outros consideravam o aluno um objeto que devia ser manuseado, moldado pelo professor. Daí a reclamação sobre indisciplina, que significava a não adequação do aluno ao seu papel de objeto; daí também a falta de depoimento sobre o aluno, porque ele não era o centro de preocupação da escola, mas conseqüência. Com os próprios se deu exatamente o contrário: o assunto disciplina não tinha importância - daí a falta de depoimentos a respeito; e quanto ao assunto aluno, os próprios reconheciam que ele estava desenvolvendo autonomia.

O tema aluno foi caracterizado por quatro traços - os outros se distribuíram entre três aspectos e os próprios se concentraram em um único. Os aspectos privilegiados pelos outros foram: 1) ausência de depoimento - sequer merece referência; 2) o aluno estar despreparado... para não ser submisso, para não ser objeto, para reclamar, para optar, para ser autônomo, para ter liberdade, etc; 3) o aluno como objeto do professor - aqui já não há o confronto do traço anterior: o aluno é bem vindo, chega até a ser querido, mas nesse bem-querer há a noção sutil do aluno como objeto do amor do professor... ele só será feliz se preencher as expectativas do professor. $\mathrm{O}$ aspecto em que se concentram os próprios é o de que os alunos estavam em processo de autonomia, uma denominação genérica para o reconhecimento de que eles tiveram mais possibilidades afetivas, lúdicas, pedagógicas, etc.

Os temas reunião e disciplina foram em conjunto os que, espontaneamente, definiram com maior clareza o que distinguia o "outro" do "próprio". Assim, havia dois extremos polarizados: os outros achavam que as reuniões não traziam resultado, opinião que não era compartilhada por qualquer dos próprios; estes, pelo contrário, consideravam que a reunião propiciava decisão coletiva, preocupação que existia exclusivamente entre estes. Numa faixa intermediária havia outros e próprios, considerando que a reunião promovia a troca de idéias; essa troca de idéias não chegava a significar integração, que se aproximaria mais de decisão coletiva. Nenhum dos entrevistados deixou de falar sobre as reuniões.

Os assuntos direção e escola/educação foram característicos dos próprios, fato confirmado pela flagrante ausência de depoimentos dos outros para os dois temas. O “outro" se preocupava com o cotidiano, com o imediato (daí a preferência pela rotina) ou com seu embaraço profissional (daí sua preocupação com a disciplina). Os próprios, ao contrário, queriam saber do resultado do seu trabalho, queriam autonomia para intervir, queriam participar, e vão medir esse resultado no aluno, na mudança qualitativa do aluno, em termos de conhecimentos ou de intervenção na realidade da escola. Os outros, quando falavam de direção, não estavam preocupados com uma diretriz assumida, e sim com o diretor, suas características pessoais, a quantidade e a forma de poder que tinha. Os próprios falavam em direção relacionada ao coletivo da escola; tinha a ver com educação no seu sentido mais amplo: Essa direção está levando para onde? O que eu posso fazer para acelerar ou frear?

O desenrolar dos acontecimentos após minha saída da direção exemplificam 
como as categorias criadas explicavam bem a atitude dos professores. Minha sucessora foi escolhida mediante processo eleitoral de intensa participação, cujas regras foram formuladas pelo próprio coletivo da escola. Após a eleição, Darcy Ribeiro, idealizador do projeto, foi derrotado por Moreira Franco na disputa para governador. No ano seguinte, a diretora eleita foi exonerada e substituída por uma interventora, para que realizasse eleições "fidedignas" na escola. A chapa que representava o projeto perdeu, e a interventora ganhou. No ano seguinte, nova eleição, mesmo resultado. Por quê?

Pesquisando as composições das chapas de acordo com tempo de escola, município, formação e turno, conclui-se que nenhum deles foi definidor de preferências, pois, em 1986 e 1987, tanto uma chapa quanto a outra misturaram todos esses dados, e em 1988, com campos bem mais demarcados, as duas chapas tinham composição idêntica: todos de São Gonçalo, com pouco tempo de escola, nível superior e turnos variados. Mas, ao analisar a composição de chapas de acordo com as categorias criadas, outros e próprios, a situação fica bem mais clara. O lado do projeto era essencialmente “próprio", com uma certa participação de outros, mas a ênfase era de próprios. Já do outro lado, as chapas foram sempre constituídas por outros, sem exceção.

Verifica-se, então, que a chapa de próprios só conseguiu se eleger uma vez, dentro do contexto político do governo Brizola e quando os próprios estavam na direção da escola. A partir da mudança de governo para Moreira Franco, os outros assumiram o poder na escola com a intervenção, e ganharam as duas eleições que se sucederam. Esses dados colocam as seguintes questões: Será que os outros, maioria na escola, votam sempre de acordo com a autoridade constituída, seja ela o diretor ou o governador? Não teriam sido os próprios beneficiados em 1986 pela mesma tendência que beneficiou os outros em 1987 e 1988?

Os outros, não se sentindo donos de seu próprio trabalho, colocando-se na posição de objetos de determinação de outros, delegam seus votos a quem consideram sujeito, as autoridades constituídas. A maneira de resistirem, a maneira de se resguardarem, a maneira de se preservarem como objetos é dizendo sempre “sim”, pois dessa forma o "não” perde seu sentido; é como um sinal de trânsito estragado: na medida em que permanece continuamente verde, perde sua função enquanto sinal. Assim, ao votarem tanto nos outros como nos próprios de acordo com a autoridade constituída, permanecem sendo objetos. Quando as coisas são colocadas dessa forma, o que de fato está ocorrendo é que as pessoas estão anulando seu próprio voto. Nesse caso, a eleição para diretor não seria nem um plebiscito, seria um referendo. Este fato revela que a eleição de diretor sem um processo de democratização das relações sociais dentro da escola faz avançar muito pouco essa passagem de objeto a sujeito de suas próprias determinações. Este sim é o processo enriquecedor que foi vivido de forma tão intensa por alunos, professores e funcionários nessa escola e que, mesmo assim, ficou muito aquém do necessário para nela democratizar as relações sociais.

\section{Cores predominantes}

Talvez se pudesse ler este predomínio de outros como a manutenção de hierarquias patriarcais em nível ideológico. Apple (1995, p. 60) nos diz:

Enquanto as mulheres lutavam para abrir o mercado de trabalho e mudar as relações patriarcais em casa e no trabalho, alguns dos argumentos usados para abrirlhes o magistério foram eficazes, mas às custas de reproduzir elementos ideológicos que estão justamente na raiz do controle patriarcal.

Chame-se a atenção para o fato de que esta delegação de poder é espontânea, há uma assimilação do patriarcalismo, ou melhor, um processo de desincorporação ainda insuficiente da autoridade masculina (Maurício, 2004). Seja como for, nosso universo entrevistado era composto por 95\% de mulheres, e apenas $62,5 \%$ ficaram na categoria outros, mostrando um processo de migração em andamento. Vale lembrar que há professores-homem na categoria outros bem como uma insuperável proporção de professoras na categoria próprios. Os outros, sejam professores-professores ou outra categoria, apesar de reafirmarem que a educação está acima da política, verdadeiramente se enquadram como um 
partido de resistência. Na definição de Caldas Aulete (1968, p. 3558), "partido político dos que temem seguir as vias do progresso e que opõem a inércia às tentativas de reformas".

Esta referência à inércia não tem nenhum caráter de condenação, já que seria inútil, como avalia Perrenoud, pois não auxilia a mudança de prática. A inércia aqui é tomada como, por mais incongruente que pareça, uma forma de ação. A aquiescência sem discussão, em ambientes de tomada de decisão, dá aparência de participação sem, entretanto, estar enraizada na representação que o grupo tem a respeito das práticas escolares. Um exemplo nítido vivenciado na experiência relatada foi o debate sobre o código de conduta.

Naquele período, na escola, foi suprimida a prática de suspender ou de expulsar aluno como forma de disciplina, tendo em vista seu caráter de exclusão socioeconômica. Esta mudança, por mais que argumentada reiteradas vezes, foi apropriada como permissividade, ou seja, o aluno pode tudo. A tensão no cotidiano chegou a tal ponto que se decidiu discutir um código de conduta para o aluno. Foram dois meses de reuniões, por área, série, geral, para que se chegasse a uma proposta. Um dos impasses foi a participação dos alunos na adoção do código. Mais claramente, foi difícil a aprovação, pelo menos, de um plebiscito, em que os alunos indicassem as normas propostas que para os alunos seriam inaceitáveis. Aprovada pelos professores e referendada pelos alunos, a proposta do código de conduta tinha como eixo a decisão coletiva: em primeira instância, pelos professores diretamente envolvidos; em segunda instância, pela coordenação pedagógica eleita. Qual o efeito prático de todo este processo de discussão? A reclamação sobre a permissividade diminuiu, pelo menos a princípio. Mas o código não saiu do papel. Se antes os professores já eram passivos em relação a problemas disciplinares, continuaram com a mesma postura. Não discutiram, não protestaram, simplesmente não agiram - daí a idéia de inércia como ação. A falta de aplicação do código não configurava uma intenção, agressiva ou não, mas revelava que os professores não consideravam o poder disciplinar como sendo seu. O mesmo sentimento que os faz se submeterem à visão implícita de autoridade faz com que não se comprometam com aquilo que diz respeito à autoridade.

Este exemplo teve a finalidade de chamar para a cena a relação entre representações e práticas. No caso, a representação dos professores outros, que predominava na escola, sobre disciplina implicava em transferir responsabilidade. O processo de discussão vivido não foi suficiente para mudar esta representação. Assim, a prática se manteve, mesmo que o contexto aparente - regras escritas e conhecidas de todos em oposição a regras inscritas no imaginário de todos - tivesse mudado. Reiterando, não é a condenação que se busca, mas maneiras de rever as práticas, que implicam mudanças de representação.

\section{Referências bibliográficas}

APPLE, Michael. Trabalho docente e textos: economia política das relações de classe e de gênero em educação. Porto Alegre: Artes Médicas, 1995.

AULETE, Caldas. Dicionário contemporâneo da língua portuguesa. 5. ed. Rio de Janeiro: Delta, 1968.

BARDIN, Laurence. Analise de Conteúdo. Lisboa: Edições 70, 2000.

LIMA, Valdileia. Cieps: a re-invenção da escola pública? 1988. Dissertação (Mestrado) Faculdade de Educação, Universidade Federal Fluminense, Niterói, 1988.

MAURÍCIO, Lúcia Velloso. Por que picharam a escola? 1990. Dissertação (Mestrado) Instituto de Estudos Avançados em Educação, Fundação Getúlio Vargas, Rio de Janeiro, 1990. 
MAURÍCIO, Lúcia Velloso. Representações de Professores num contexto de mudança. In: CONGRESSO INTERNACIONAL DE EDUCAÇÃO E TRABALHO. [Anais...]. Aveiro, Portugal, 2005. CD-ROM.

MAURÍCIO, Lúcia Velloso. Possibilidades e limites de participação de professores. In: ENDIPE, 13. [Anais...]. Curitiba, 2004. CD-ROM.

MIGNOT, Ana Cristina. Ciep: alternativa para a qualidade de ensino ou nova investida do populismo em educação? Dissertação (Mestrado) - Faculdade de Educação, Pontifícia Universidade Católica do Rio de Janeiro, Rio de Janeiro, 1988.

NILDECOFF, Maria Teresa. Uma escola para o povo. 32. ed. São Paulo: Brasiliense, 1991.

PERRENOUD, Philippe. Práticas pedagógicas, profissão docente e formação. Lisboa: Publicações Dom Quixote, 1993.

RIBEIRO, Darcy. O livro dos Cieps. Rio de Janeiro: Bloch Editores, 1986.

RIO DE JANEIRO (Estado). Escola viva - viva a escola no. 1 e 2. Rio de Janeiro: Programa Especial de Educação, 1983a.

. Plano de Desenvolvimento Econômico e Social do Estado do Rio de Janeiro, 1984/1987. Diário Oficial do Rio de Janeiro, Lei RJ 705, de 21 de dezembro, 1983b.

Falas ao professor. Rio de Janeiro: Programa Especial de Educação, 1985.

Lúcia Velloso Maurício, doutora em Educação pela Universidade Federal do Rio de Janeiro (UFRJ), é professora adjunta do mestrado em Educação da Universidade Estácio de Sá (Unesa) e da Faculdade de Formação de Professores da Universidade Estadual do Rio de Janeiro (Uerj) e consultora da Fundação Darcy Ribeiro.

luciavelloso@terra.com.br

Recebido em 14 de junho de 2006.

Aprovado em 11 de setembro de 2006. 